\title{
Microstructure Evolution in the Near-Surface Region During Homogenization of a Twin-Roll Cast AlFeMnSi Alloy
}

\author{
JUNJIE WANG, XIAORONG ZHOU, GEORGE E. THOMPSON, JOHN A. HUNTER, \\ and YUDIE YUAN
}

A near-surface deformed layer, comprising ultrafine grains of 50-500 $\mathrm{nm}$ diameters with the grain boundaries being decorated by a high population density of fine cubic $\alpha-\mathrm{Al}_{15}(\mathrm{FeMn})_{3} \mathrm{Si}_{2}$ dispersoids and oxide/lubricant particles, was generated in a foil stock AlFeMnSi alloy during twin-roll casting due to severe shear deformation within the near-surface region. During a subsequent multi-step homogenization treatment at temperatures in the range of $713 \mathrm{~K}$ and $853 \mathrm{~K}\left(440{ }^{\circ} \mathrm{C}\right.$ and $\left.580{ }^{\circ} \mathrm{C}\right)$, the fine cubic $\alpha-\mathrm{Al}_{15}(\mathrm{FeMn})_{3} \mathrm{Si}_{2}$ dispersoids within the near-surface layer were dissolved, while sparse, large lath-shaped $\mathrm{Al}_{3} \mathrm{Fe}$ particles formed in the same region. Significant grain growth took place within the near-surface layer due to the loss of grain boundary pinning by the dispersoids, leading to the removal of the ultrafine-grained microstructure within the near-surface region. However, at local regions where the population density of oxide particles was sufficiently high to provide grain boundary pinning, the ultrafine-grained microstructure was preserved within the near-surface layer.

DOI: $10.1007 / \mathrm{s} 11661-016-3568-6$

(C) The Author(s) 2016. This article is published with open access at Springerlink.com

\section{INTRODUCTION}

RECENT investigations on thermo-mechanically processed aluminum alloys have revealed near-surface deformed layers ${ }^{[1-7]}$ which have significant influences on electrochemical properties, corrosion performance, optical properties, etc. ${ }^{4,6,8-18]}$ The near-surface deformed layers are characterized by an ultrafine-grained microstructure, consisting of a large population of grain boundaries which represents high stored energy. At elevated temperatures, the ultrafine grains in the near-surface deformed layer are susceptible to grain growth. However, the thermal stability of near-surface layers on aluminum alloys is enhanced if a high population density of incorporated oxide particles $[2,4,19]$ and/or dispersed intermetallic precipitates ${ }^{[11]}$ is present at the grain boundaries. Both types of particles can effectively retard the movement of grain boundaries through the Zener drag pinning effect. Zhou et al. ${ }^{[2]}$ reported that the near-surface layer comprising a high population density of rolled-in oxide particles in a rolled AA3005 alloy survived an annealing treatment at $623 \mathrm{~K}$ $\left(350{ }^{\circ} \mathrm{C}\right)$ for 2 hours, while the near-surface layer free of oxides was annealed out. Scamans et al. ${ }^{[4]}$ reported that the near-surface layers produced by mechanical grinding

JUNJIE WANG, Visiting Academic, and XIAORONG ZHOU and GEORGE E. THOMPSON, Professors, are with the School of Materials, The University of Manchester, Manchester, M13 9PL, UK. Contact e-mail: xiaorong.zhou@manchester.ac.uk JOHN A. HUNTER, Group Leader, and YUDIE YUAN, Lead Surfaces Scientist and Corrosion Specialist, are with Novelis Global Research and Technology Center, Kennesaw, GA 30144.

Manuscript submitted March 20, 2015.

Article published online June 1, 2016 were much less thermally stable than those generated by hot rolling due to the insufficient level of incorporated oxides for pinning the grain boundaries. A previous investigation on copper alloys reported that with sufficient closely spaced, thermally stable particles, the deformed/recovered microstructure could be preserved up to the melting point of the alloy matrix. ${ }^{[20]}$ However, up to date, no work on whether or not the ultrafine-grained microstructure in the near-surface layer with a high population density of oxide particles and/or intermetallic precipitates in aluminum alloy can survive exposure to high temperatures, i.e., homogenization, has been reported. Further, the authors' previous work revealed that the distribution of the oxide/lubricant particles within the near-surface layer of foil stock twin-roll cast (TRC) $8906 \mathrm{AlFeSi}$ alloy was not uniform due to the varying extents of local tool/workpiece interaction. ${ }^{[21]}$ The influence of the local population densities of the oxide/lubricant particles on the thermal stability of the near-surface layer has not been reported. Although elemental redistribution and intermetallic phase transformation in the bulk of continuously cast AlFeMnSi alloys during high temperature annealing has been reported previously, ${ }^{22,23]}$ the response of intermetallic precipitates in the near-surface layers of TRC aluminum alloys to the homogenization treatment has yet to be investigated. The subsequent influence on the evolution of the near-surface layers during homogenization is unknown.

The present work investigates the evolution of the near-surface layer in a foil stock TRC AlFeMnSi alloy during a commercial multi-step homogenization treatment. The microstructure within the surface/near-surface region of the as-cast strip and the homogenized 
counterpart were characterized by using scanning and transmission electron microscopy. The response of intermetallic precipitates in the near-surface region to the homogenization treatment and the subsequent influence on the evolution of the near-surface layers are studied. Further, the influence of the local population density of oxide/lubricant particles on the thermal stability of the near-surface layer is discussed.

\section{EXPERIMENTAL}

Commercial foil stock of an AlFeMnSi alloy (Fe 1.52 wt pet, $\mathrm{Mn} 0.39$ wt pet, Si 0.20 wt pet, $\mathrm{Cu} 0.16$ wt pet, Mg 0.0025 wt pet, Ti 0.021 wt pet, Zn 0.009 wt pet, Al bal.) was supplied by Novelis as $6.5-\mathrm{mm}$-thick strips in the as twin-roll cast and homogenized conditions. The soaking temperatures for the multi-step homogenization treatment were in the range of $713 \mathrm{~K}$ and $853 \mathrm{~K}\left(440{ }^{\circ} \mathrm{C}\right.$ and $580^{\circ} \mathrm{C}$ ). SEM was employed to characterize the surface features of both the as-cast and homogenized strips. The characterization of the microstructure in the near-surface regions of both the as-cast and homogenized strips was performed on ultramicrotomed cross sections, which were cut with a diamond knife on an ultramicrotome. Ultramicrotomy is an effective technique for preparing cross-sectional SEM and TEM specimens from precisely located surface features. ${ }^{[4]}$ The ultramicrotomed cross-sectional blocks were examined in a FEG-SEM. The corresponding ultramicrotomed cross-sectional foils with a nominal thickness of $15 \mathrm{~nm}$ were collected on 400-mesh nickel grids and then examined with TEM.

\section{RESULTS AND DISCUSSION}

\section{A. Twin-Roll Cast Strip}

Figure 1 shows scanning electron micrographs of the TRC AlFeMnSi alloy strip surface. The secondary electron micrograph in Figure 1(a) shows shingles, rolling ridges, and grooves on the alloy surface. In the corresponding backscattered electron micrograph at an increased magnification, as shown in Figure 1(c), a high population density of ultrafine bright spots (as indicated by the arrows) is evident, which are intermetallic particles in the surface/near-surface region of the strip.

A transverse cross section of the alloy was produced by ultramicrotomy. The cutting location is indicated by the dashed line in Figure 1(a). Figure 2 shows the scanning electron micrographs of the surface/near-surface region of the ultramicrotomed cross section. Figure 2(a) shows the profile of the shingle. Three steps are evident at the edge on the left side of the shingle, indicating repeated smearing at this site. The right side of the shingle is partially separated from the bulk alloy (as indicated by the arrow), suggesting that the metal at this site was smeared across the strip surface during the TRC process. Figure 2(b) shows the microstructure within the framed area in Figure 2(a), revealing a characteristic near-surface layer with varying
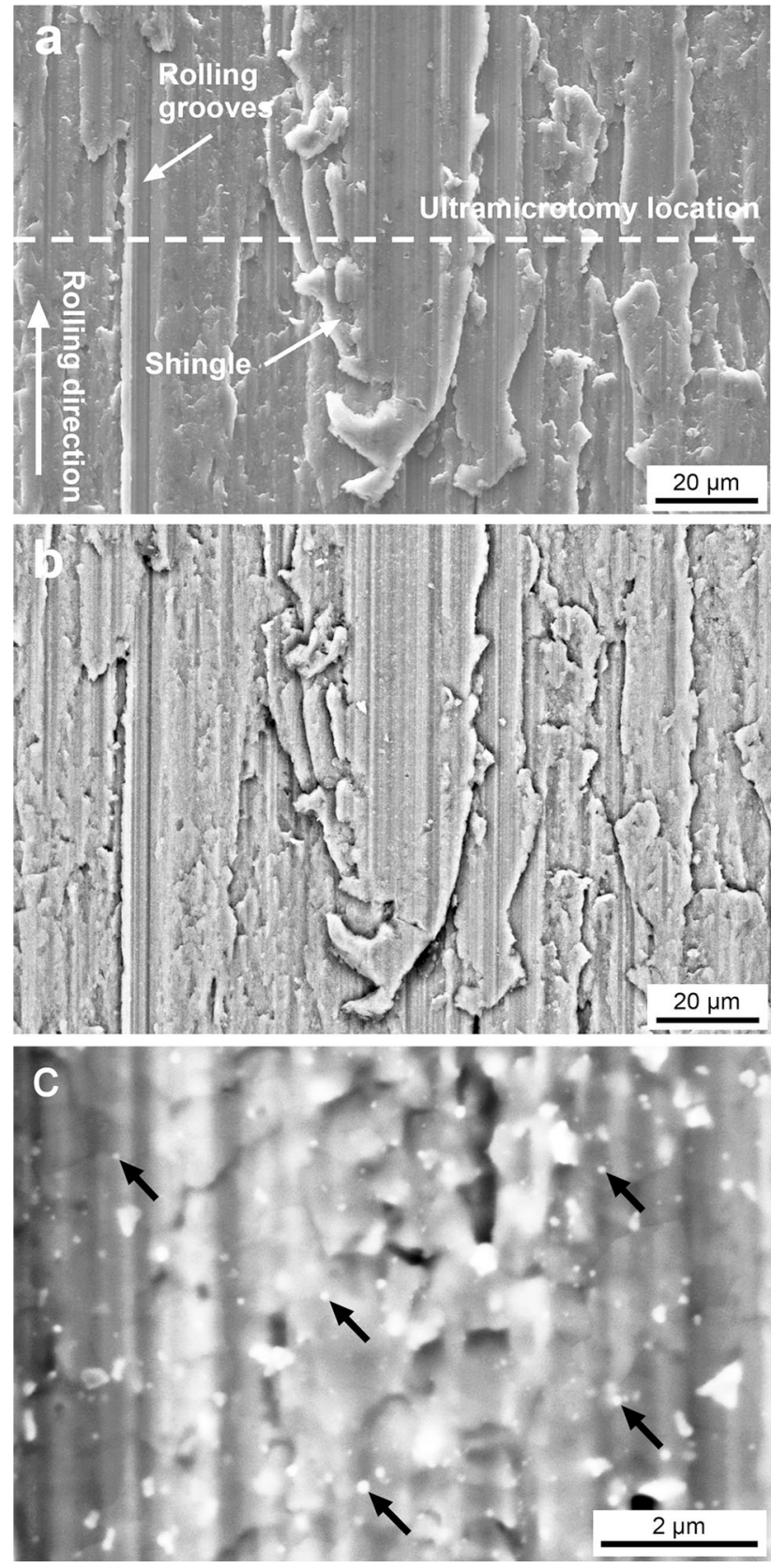

Fig. 1-Scanning electron micrographs of a shingling area on twin-roll cast AlFeMnSi alloy strip surface: (a) secondary electron micrograph; $(b)$ corresponding backscattered electron micrograph of (a); (c) backscattered electron micrograph at an increased magnification.

thicknesses within the shingle. The interface between the near-surface layer and the underlying bulk alloy is highlighted by the white dashed curve. In the 'low' region left to the framed area in Figure 2(b), no near-surface layer was found due to a relatively low level of local shear strain. High population densities of fine bright spots (nano-sized intermetallic dispersoids) and fine dark spots are evident within the near-surface layer. Figure 2(c) shows a backscattered electron micrograph of the framed area in Figure 2(b), showing that the grain size within the near-surface layer ranges from 

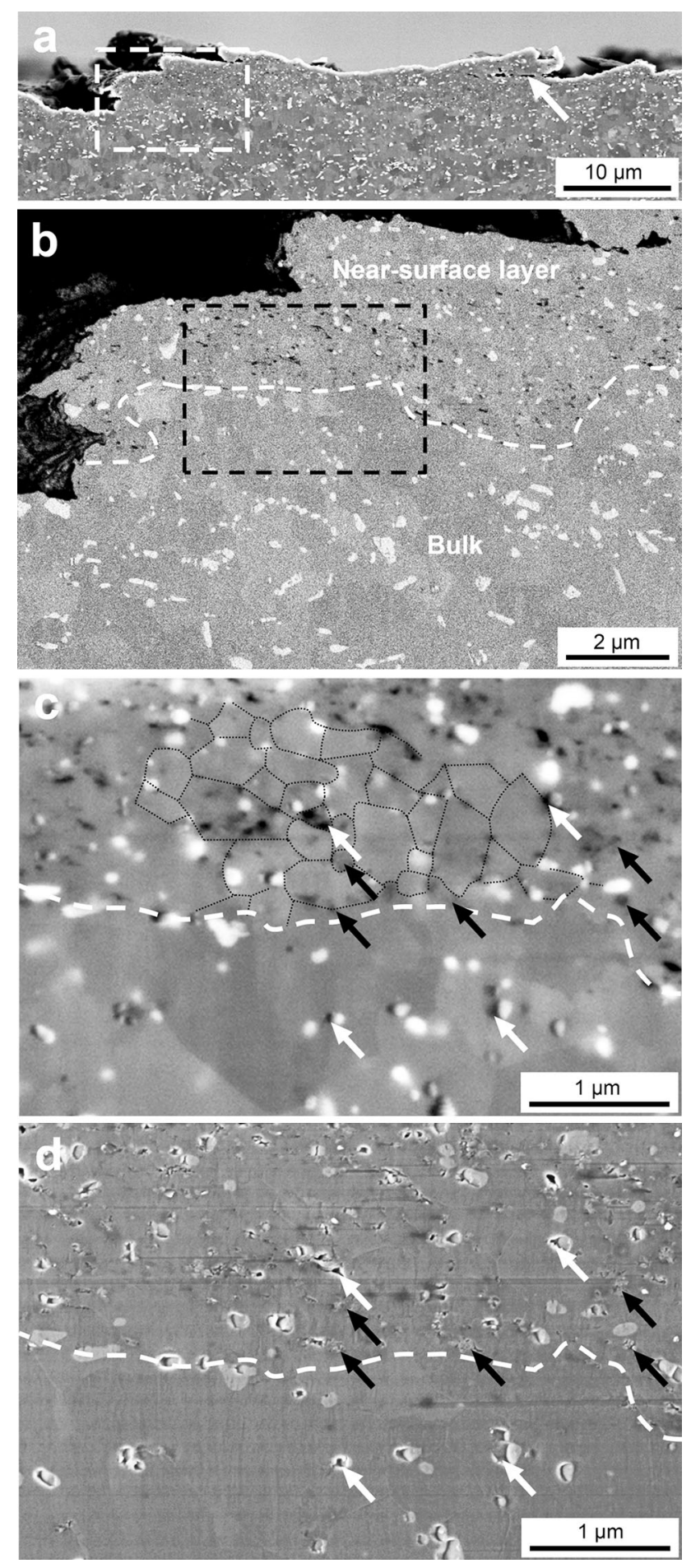

Fig. 2-Scanning electron micrographs of the ultramicrotomed transverse cross section of the as-cast AlFeMnSi alloy strip: (a) backscattered electron micrograph; $(b)$ the framed area in (a) at an increased magnification; $(c)$ the framed area in (b) at an increased magnification; (d) corresponding secondary electron micrograph of (c).

50 to $500 \mathrm{~nm}$ (some of the grain boundaries are highlighted with dot lines), while that in the underlying bulk region varies in the range of $0.5-2 \mu \mathrm{m}$. The grain refinement in the near-surface layer was caused by the high level of shear deformation in the near-surface region of the alloy during the twin-roll cast process. ${ }^{[21]}$ Two types of dark spots are shown in the backscattered electron micrograph. The first type is voids, as indicated by white arrows. Voids appear as dark spots as well in the secondary electron micrograph (Figure 2(d)). Some of the voids were generated by the dragging-out of the intermetallic particles during the ultramicrotomy process. The second type of dark spots is indicated by black arrows in Figure 2(c), representing second-phase particles rather than voids, as can be distinguished from the secondary electron micrograph. The dark appearance of these particles in the backscattered electron micrograph indicates the presence of elements with a relatively small atomic number compared to aluminum, thus, exhibiting the distribution of oxide particles. This was confirmed by composition analysis in TEM.

Electron transparent specimens were produced from the same location on the TRC AlFeMnSi alloy strip, as indicated by the dashed line in Figure 1(a). Figure 3 shows the bright field transmission electron micrographs of the near-surface region of the TRC strip, revealing ultrafine grains. Fine spherical intermetallic dispersoids with diameters ranging from 30 to $150 \mathrm{~nm}$ are also evident, as indicated by the arrows in Figure 3(a). EDX analysis revealed that the dispersoids mainly contain Al, $\mathrm{Fe}, \mathrm{Mn}$, and $\mathrm{Si}$, as shown in Figure 4. The Ni signal was from the $\mathrm{Ni}$ grid used for supporting the ultramicrotomed foils. An atomic $(\mathrm{Fe}+\mathrm{Mn}) / \mathrm{Si}$ ratio of about 1.5 was revealed by quantitative analysis. Figure 5 shows a lattice image of the dispersoid within the near-surface layer, confirming that the dispersoids were cubic $\alpha-\mathrm{Al}_{15}(\mathrm{FeMn})_{3} \mathrm{Si}_{2}$ phase. These cubic $\alpha-\mathrm{Al}_{15}(\mathrm{FeMn})_{3} \mathrm{Si}_{2}$ dispersoids were located at grain boundaries within the near-surface layer, pinning the grain boundaries through the Zener drag effect. The presence of cubic $\alpha-\mathrm{Al}_{15}(\mathrm{FeMn})_{3} \mathrm{Si}_{2}$ dispersoids was a result of preferential precipitation in the near-surface layer. Similar phenomenon has been reported on a variety of aluminum alloys. ${ }^{[2,4,11,19,21,24]}$

Figure 3(b) shows a high population density of oxide particles with sizes ranging from 20 to $150 \mathrm{~nm}$ within the near-surface layer of the TRC AlFeMnSi alloy strip, as indicated by the arrows. The composition of the particles was confirmed by EDX analysis, as shown in Figure 6. On some oxide particles, carbon was also detected (Figure 6(b)), indicating rolled-in lubricant residue. These oxide/lubricant residue particles were incorporated into the near-surface region of the alloy strip due to the interaction between the surfaces of the rolls and the solidified workpiece during twin-roll casting. ${ }^{[21]}$ The more severe local tool/workpiece interaction results in higher level of incorporation. Consequently, the distribution of the oxide/lubricant particles within the near-surface layer is not uniform, e.g., the top left area of the micrograph in Figure 3(a) shows less oxide/lubricant particles. These oxide/lubricant particles were also located at grain boundaries within the near-surface layer and had a similar effect on pinning the grain boundaries as the cubic $\alpha-\mathrm{Al}_{15}(\mathrm{FeMn})_{3} \mathrm{Si}_{2}$ dispersoids. 

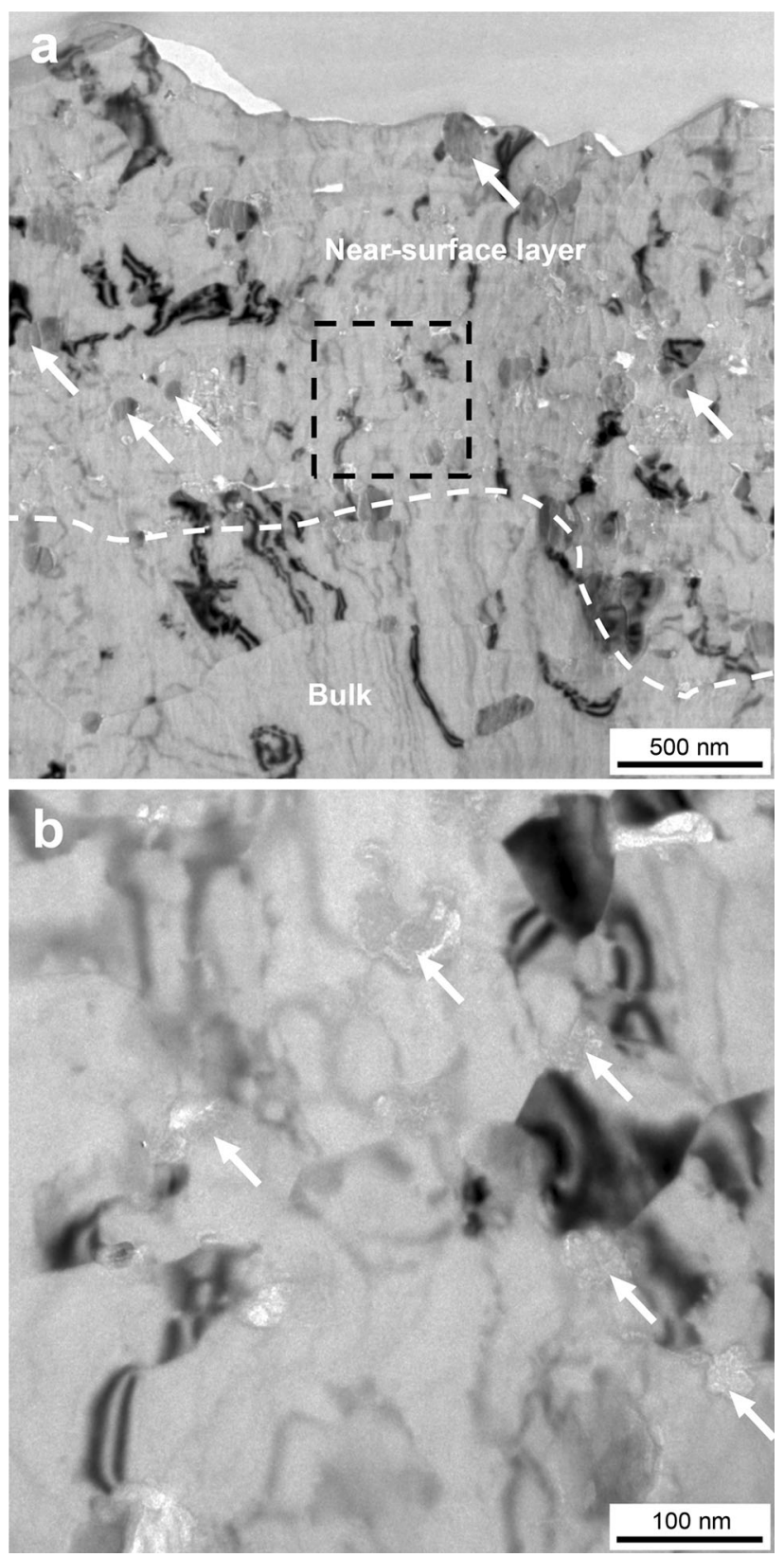

Fig. 3- (a) Bright field transmission electron micrograph of an ultramicrotomed transverse cross-sectional foil taken from the as-cast $\mathrm{AlFeMnSi}$ strip, showing the microstructure within the near-surface region; (b) the framed area in (a) at an increased magnification.

\section{B. Homogenized Strip}

Figure 7 shows the scanning electron micrographs of the homogenized AlFeMnSi alloy strip surface. The homogenization treatment did not modify the strip surface profile (Figure 7(a)). However, modification of the microstructure in the surface/near-surface region of the alloy strip was evident in terms of the population density and the shape of intermetallic particles. Figure 7(b) and (c) shows backscattered electron micrographs of the homogenized strip surface. Unlike those of the as-cast strip, intermetallic particles in the surface/ near-surface region of the homogenized strip are

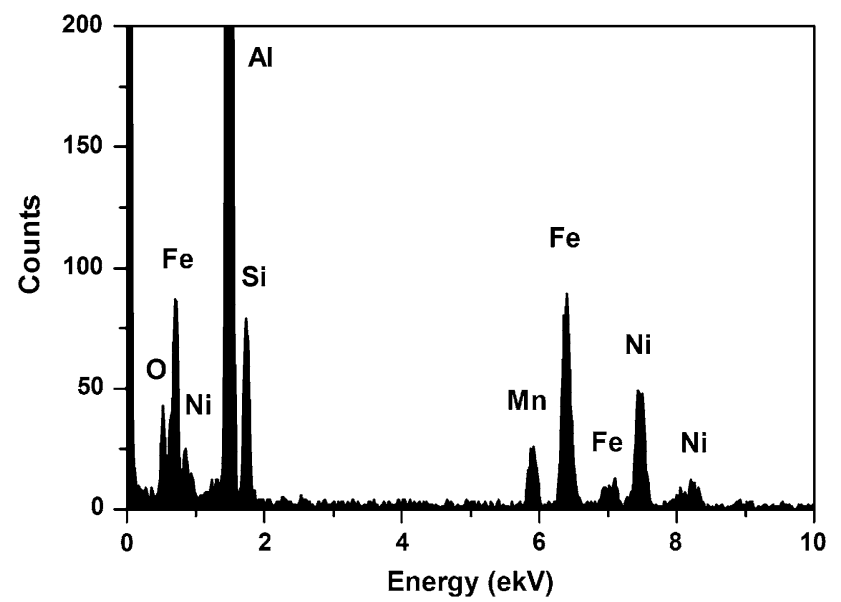

Fig. 4-EDX spectrum of the spherical intermetallic particle within the near-surface layer, as indicated by arrows in Fig. 3a.

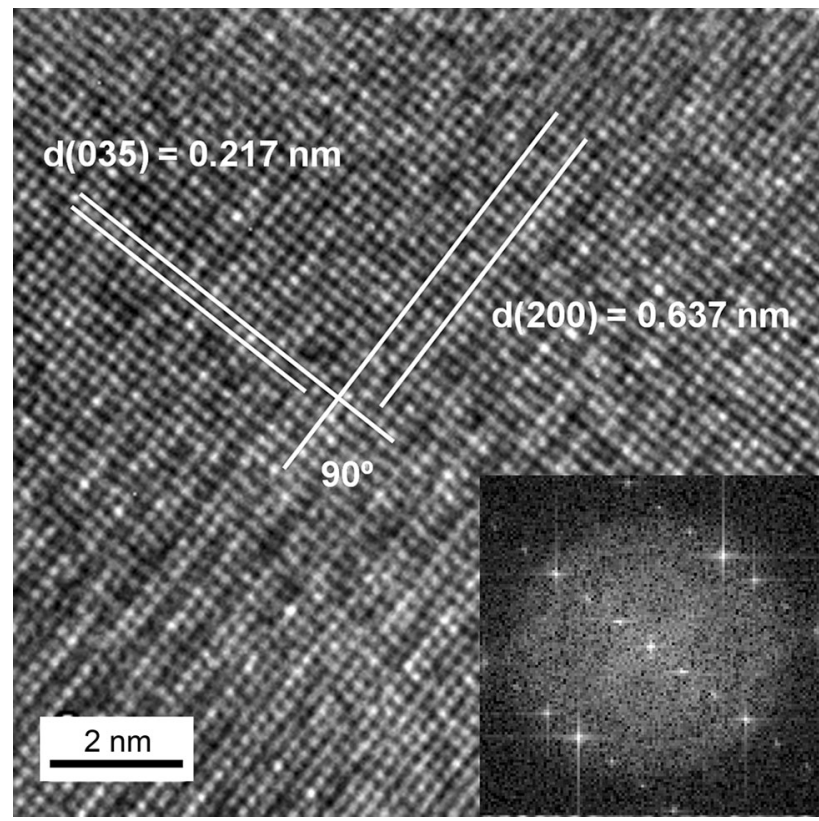

Fig. 5-Lattice image of a spherical intermetallic particle within the near-surface layer in the twin-roll cast $\mathrm{AlFeMnSi}$ alloy viewed along the [05-3] axis, inset: Fast Fourier Transformation of the lattice image.

significantly coarsened and the population density of intermetallic particles is significantly reduced. Randomly distributed lath-shaped intermetallic particles are evident, as indicated by the arrows in Figure 7(b) and (c). The length of these particles varied in the range of 5-15 $\mu \mathrm{m}$, with an aspect ratio ranging between 3 and 10.

A cross section was produced from the homogenized strip by ultramicrotomy along the dashed line in Figure 7(a). Figure 8 shows the backscattered electron micrographs of the near-surface region of the ultramicrotomed cross section. Figure 8(a) shows that the large lath-shaped particles were mainly present within shingles where the near-surface deformed layer was located 


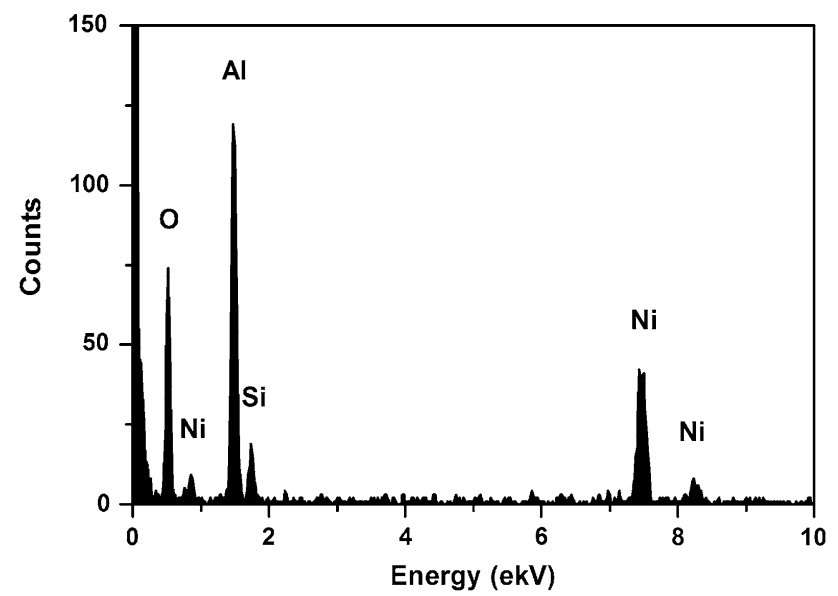

(a)

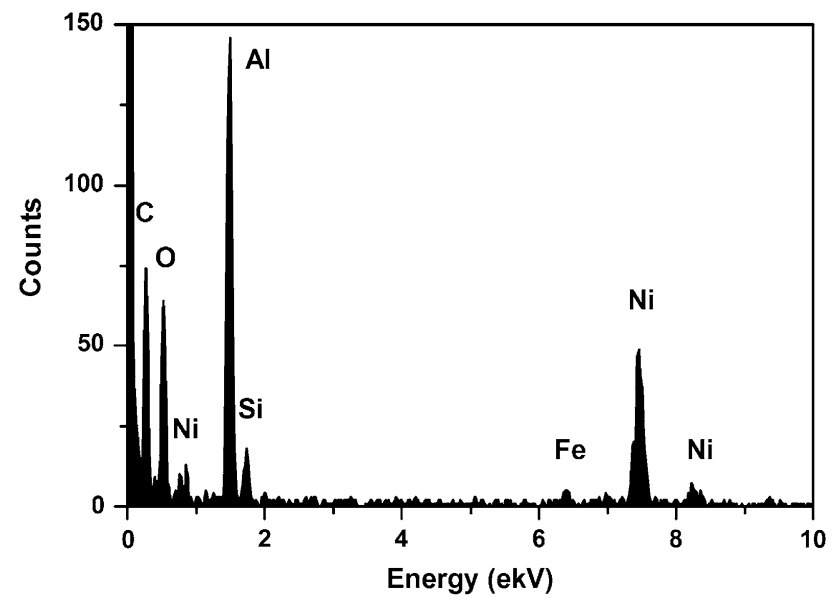

(b)

Fig. 6-EDX spectra of the oxide particles within the near-surface layer, as indicated by arrows in Fig. 3(b).

in the TRC alloy. In a relatively flat surface area, no such particles were observed in the near-surface region, as shown by the right one-fourth of the micrograph. Figure 8(b) shows the microstructure within the framed area in Figure 8(a). A lath-shaped particle is located about $3 \mu \mathrm{m}$ below the strip surface. EDX analysis detected mainly $\mathrm{Al}$ and $\mathrm{Fe}$, as displayed in the inset of Figure 8(b). A low content of Mn (0.39 at. pet) was also detected, giving an atomic $\mathrm{Fe} / \mathrm{Mn}$ ratio of 21. Common intermetallic phases in foil stock $\mathrm{AlFeMnSi}$ alloys (AA8006 type) are $\alpha$-AlFeMnSi, $\mathrm{Al}_{3} \mathrm{Fe}, \quad$ and $\mathrm{Al}_{6}(\mathrm{FeMn}) .{ }^{[25,26]}$ In the crystal structure of $\mathrm{Al}_{3} \mathrm{Fe}, \mathrm{Mn}$ can substitute $\mathrm{Fe}$ to a maximum solubility of $4-5$ pct. ${ }^{[25]}$ Therefore, the lath-shaped particles are assigned to the $\mathrm{Al}_{3} \mathrm{Fe}$ phase with a limited content of Mn. A phenomenon accompanying the presence of the lath-shaped $\mathrm{Al}_{3} \mathrm{Fe}$ particle was the disappearance of the fine cubic $\alpha-\mathrm{Al}_{15}(\mathrm{FeMn})_{3} \mathrm{Si}_{2}$ dispersoids in the same region after the homogenization treatment. The relatively high temperatures (in the range of $713 \mathrm{~K}$ and $853 \mathrm{~K}$ $\left(440{ }^{\circ} \mathrm{Cand} 580{ }^{\circ} \mathrm{C}\right)$ ) applied in the multi-step homogenization treatment caused the dissolution of the fine cubic $\alpha-\mathrm{Al}_{15}(\mathrm{FeMn})_{3} \mathrm{Si}_{2}$ dispersoids ${ }^{[22]}$ and the subsequent formation of $\mathrm{Al}_{3} \mathrm{Fe}$ particles. ${ }^{[23]}$ The large
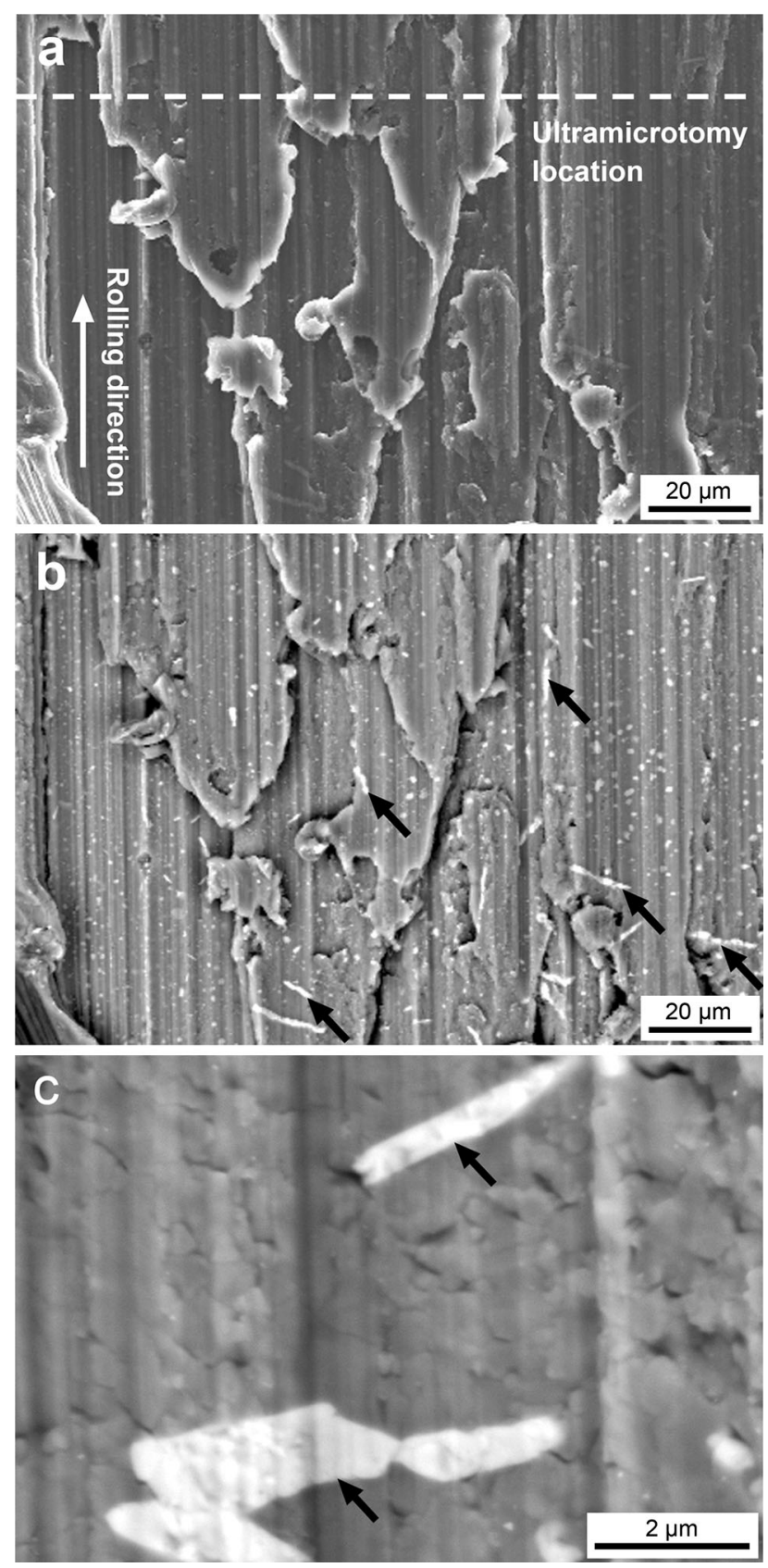

Fig. 7- Scanning electron micrographs of a shingling area on the homogenized AlFeMnSi alloy strip surface: $(a)$ secondary electron micrograph; $(b)$ corresponding backscattered electron micrograph of (a); (c) backscattered electron micrograph at an increased magnification.

population of grain boundaries within the near-surface layer was likely to promote the mobility of alloying atoms and, therefore, the $\alpha-\mathrm{Al}_{15}(\mathrm{FeMn})_{3} \mathrm{Si}_{2}$ phase dissolution kinetics. The dissolved $\mathrm{Fe}$ atoms within the near-surface region diffused toward the newly formed $\mathrm{Al}_{3} \mathrm{Fe}$ particles, resulting in the coarsening of the particles in the near-surface region of the homogenized strip. Associated with the dissolution of $\alpha-\mathrm{Al}_{15}(\mathrm{FeMn})_{3} \mathrm{Si}_{2}$ phase, grains in the same region were coarsened significantly during the homogenization treatment. 

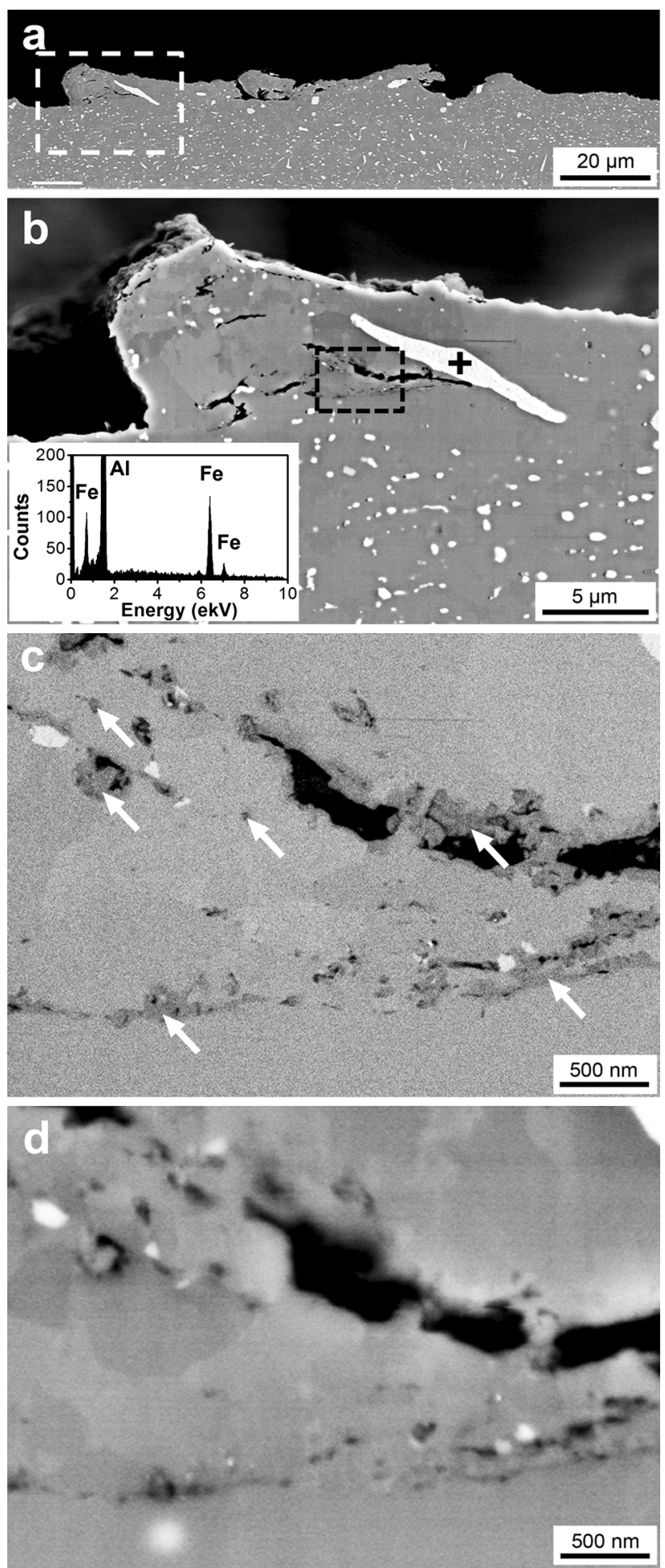

Fig. 8- (a) Backscattered electron micrographs of the ultramicrotomed transverse cross section of homogenized AlFeMnSi alloy strip; (b) the framed area in (a) at an increased magnification, inset: EDX spectrum taken from the lath-shaped intermetallic particle indicated by "+"; $(c)$ the framed area in (b) (accelerating voltage $1.5 \mathrm{kV}) ;(d)$ the framed area in (b) (accelerating voltage $8.0 \mathrm{kV})$.

Some hollowed areas in the near-surface region appeared as dark bands in Figure 8(b), indicating that shingles were partially separated to the bulk alloy, which
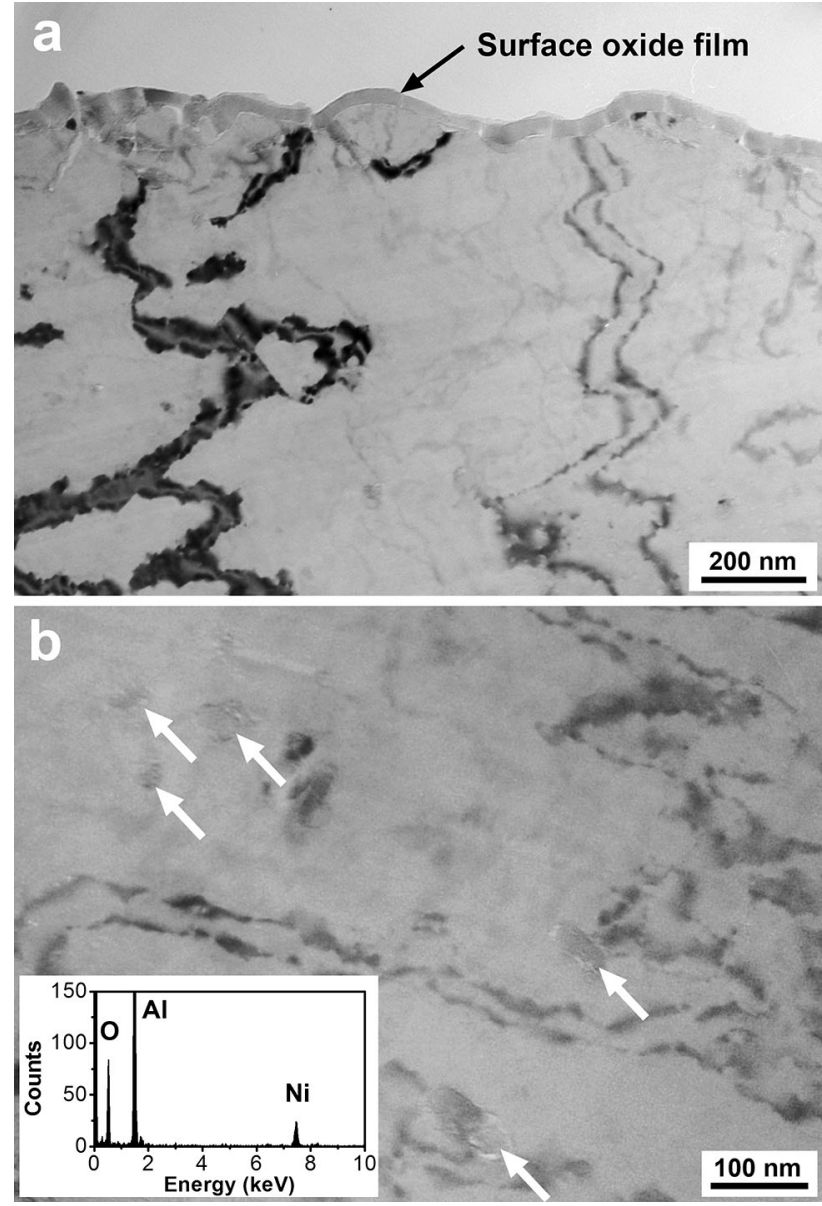

Fig. 9- (a) Bright field transmission electron micrograph of an ultramicrotomed transverse cross-sectional foil taken from the homogenized AlFeMnSi strip, showing the microstructure within the near-surface region; $(b)$ at an increased magnification, inset: EDX spectrum of the oxide particle, as indicated by arrows in (b).

is consistent with the observations of the TRC strip (Figure 2). In the adjacent regions of the dark bands, a high population density of oxide particles was observed, as indicated by the arrows in Figure 8(c). A few ultrafine grains (revealed by channeling contrast of the backscatter electrons) are evident at these sites (Figure 8(d)), indicating that these ultrafine grains survived from the grain growth during the homogenization treatment.

Electron transparent specimens were taken from the same location of the homogenized AlFeMnSi alloy strip, as indicated by the dashed line in Figure 7(a). Figure 9 shows the bright field transmission electron micrographs of the surface/near-surface region. An air-formed surface oxide layer, with a thickness of about $30 \mathrm{~nm}$, was present due to the high homogenization temperature (Figure 9(a)). The ultrafine-grained near-surface layer was absent. At an increased magnification, some randomly distributed dark spots can be seen in the near-surface region, as indicated by the arrows in Figure 9(b). Most of these dark spots were located in the interior of grains. The inset of Figure 9(b) displays the EDX spectrum acquired at a dark spot, suggesting the presence of an oxide particle. 
During the homogenization of the AlFeMnSi alloy, the grain growth in the near-surface region was controlled mainly by two opposing factors. The stored energy associated with the large population of grain boundaries in the near-surface layer provided driving force for the grain growth, while the dispersed oxide/ lubricant particles and the $\alpha-\mathrm{Al}_{15}(\mathrm{FeMn})_{3} \mathrm{Si}_{2}$ dispersoids retarded the movement of the grain boundaries by Zener drag effect. The magnitude of Zener drag is positively related to the population density of these dispersed particles. ${ }^{[20]}$ Grain growth occurs if the overall population density of these particles is lower than a certain critical value. As a result of the dissolution of $\alpha-\mathrm{Al}_{15}(\mathrm{FeMn})_{3} \mathrm{Si}_{2}$ dispersoids in the near-surface layer during homogenization treatment, the resistance to the movement of grain boundaries decreased substantially. The Zener drag effect was then mainly provided by the oxide/lubricant particles. As described above, the distribution of the oxide/lubricant particles within the near-surface layer was not uniform. In some local regions where the population density of oxide/lubricant particles was sufficiently high for efficient Zener pinning of the grain boundaries, the ultrafine grains were preserved within the near-surface layer. In other regions where the Zener pinning of the grain boundaries by the oxide/lubricant particles was insufficient, grain coarsening occurs.

\section{CONCLUSIONS}

1. A near-surface layer, comprising ultrafine grains of $50-500 \mathrm{~nm}$ diameter and high population density of grain boundary oxide/lubricant particles (20-150 $\mathrm{nm}$ size) and cubic $\alpha-\mathrm{Al}_{15}(\mathrm{FeMn})_{3} \mathrm{Si}_{2}$ dispersoids (30-150 nm diameter), is present on the TRC $\mathrm{AlFeMnSi}$ alloy. The near-surface layer is stable at ambient temperature since the grain boundaries within the near-surface layer are pinned by the oxide/lubricant particles and the dispersoids.

2. During the multi-step homogenization treatment at temperatures in the range of $713 \mathrm{~K}$ and $853 \mathrm{~K}$ $\left(440{ }^{\circ} \mathrm{C}\right.$ and $580{ }^{\circ} \mathrm{C}$ ), the highly dispersed $\alpha-\mathrm{Al}_{15}$ $(\mathrm{FeMn})_{3} \mathrm{Si}_{2}$ dispersoids within the near-surface layer were dissolved. Subsequently, sparse lath-shaped $\mathrm{Al}_{3} \mathrm{Fe}$ particles with lengths varying from 5 to $15 \mu \mathrm{m}$ and aspect ratio ranging between 3 and 10 formed in the same region.

3. As a consequence of the dissolution of $\alpha-\mathrm{Al}_{15}$ $(\mathrm{FeMn})_{3} \mathrm{Si}_{2}$ dispersoids, Zener drag pinning effect reduced significantly and, hence, remarkable grain growth took place in the near-surface region. However, at local regions where the population density of oxide/lubricant particles was sufficiently high for efficient Zener pinning at the selected homogenization temperatures, the ultrafine-grained near-surface layer survived the homogenization treatment.

\section{ACKNOWLEDGMENTS}

The authors wish to thank the UK Engineering and Physical Sciences Research Council for support of the LATEST2 Programme Grant. China Scholarship Council and Novelis are also acknowledged for provision of financial support.

\section{OPEN ACCESS}

This article is distributed under the terms of the Creative Commons Attribution 4.0 International License (http://creativecommons.org/licenses/by/4.0/), which permits unrestricted use, distribution, and reproduction in any medium, provided you give appropriate credit to the original author(s) and the source, provide a link to the Creative Commons license, and indicate if changes were made.

\section{REFERENCE}

1. K. Li, X. Zhou, G.E. Thompson, J.A. Hunter, and Y. Yuan: Mater. Sci. Forum, 2013, vol. 765, pp. 358-62.

2. X. Zhou, Y. Liu, G.E. Thompson, G. Scamans, P. Skeldon, and J. Hunter: Metall. Mater. Trans. A, 2011, vol. 42A, pp. $1373-85$.

3. Y. Liu, M.F. Frolish, W.M. Rainforth, X. Zhou, and G.E. Thompson: G.M. Scamans andJ.A. HunterSurf. Interface Anal., 2010, vol. 42, pp. 180-84.

4. G.M. Scamans, M.F. Frolish, W.M. Rainforth, Z. Zhou, Y. Liu, X. Zhou, and G.E. Thompson: Surf. Interface Anal., 2010, vol. 42, pp. $175-79$.

5. G.M. Scamans, A. Afseth, G.E. Thompson and X. Zhou: Proc. 2nd Int. Conf. Alum. Surf. Sci. Technol., Manchester, UK, 2000, pp. $9-16$.

6. H. Leth-Olsen, J.H. Nordlien, and K. Nisancioglu: Corros. Sci., 1998, vol. 40, pp. 2051-63.

7. M. Fishkis and J.C. Lin: Wear, 1997, vol. 206, pp. 156-70.

8. J. Wang, X. Zhou, G.E. Thompson, J.A. Hunter, and Y. Yuan: Mater. Charact., 2015, vol. 99, pp. 109-17.

9. B. Liu and X. Zhou: Mater. Sci. Forum, 2014, vol. 794-796, pp. 217-22.

10. Y. Liu, A. Laurino, T. Hashimoto, X. Zhou, P. Skeldon, G.E. Thompson, G.M. Scamans, and C. Blanc: W.M. Rainforth and M.F. FrolishSurf. Interface Anal., 2010, vol. 42, pp. 185-88.

11. Y. Liu, X. Zhou, G.E. Thompson, T. Hashimoto, G.M. Scamans, and A. Afseth: Acta. Mater., 2007, vol. 55, pp. 353-60.

12. P. Premendra, J.H. Chen, F.D. Tichelaar, H. Terryn, J.H.W.L. deWit, and L. Katgerman: Surf. Coat. Technol., 2007, vol. 201, pp. 4561-70.

13. X. Zhou, G.E. Thompson, and G.M. Scamans: Corros. Sci., 2003, vol. 45 , pp. $1767-77$.

14. A. Afseth, J.H. Nordlien, G.M. Scamans, and K. Nisancioglu: Corros. Sci., 2001, vol. 43, pp. 2093-109.

15. K. Nisancioglu, J.H. Nordlien, A. Afseth, and G.M. Scamans: Mater. Sci. Forum, 2000, vols. 331-337, pp. 111-26.

16. I. Lindseth: PhD Thesis, Norwegian University of Science and Technology, Trondheim, 1999.

17. H. Leth-Olsen and K. Nisancioglu: Corros. Sci., 1998, vol. 40, pp. 1179-94.

18. H. Leth-Olsen, A. Afseth, and K. Nisancioglu: Corros. Sci., 1998, vol. 40 , pp. $1195-214$

19. A. Afseth, J.H. Nordlien, G.M. Scamans, and K. Nisancioglu: Corros. Sci., 2001, vol. 43, pp. 2359-77. 
20. F.J. Humphreys and M. Hatherly: Recrystallization and Related Annealing Phenomena, 2nd ed., Elsevier, Amsterdam, 2004.

21. J. Wang, X. Zhou, G.E. Thompson, J.A. Hunter, and Y. Yuan: Metall. Mater. Trans. A, 2015, vol. 46A, pp. 2688-95.

22. M. Slamova, V. Ocenasek, M. Cieslar, B. Chalupa, and P. Merle: Mater. Sci. Forum, 2000, vols. 331-337, pp. 829-34.

23. Y. Birol and F. Sertcelik: Int. J. Mater. Res., 1999, vol. 90, pp. 329-34.
24. G.M. Scamans, A. Afseth, G.E. Thompson, and X. Zhou: Mater. Sci. Forum, 2002, vols. 369-402, pp. 1461-66.

25. N.A. Belov, D.G. Eskin, and A.A. Axenov: Multicomponent Phase Diagrams: Applications for Commercial Aluminum Alloys, Elsevier, Amsterdam, 2005, pp. 1-10.

26. M. Warmuzek, K. Rabczak, and J. Sieniawski: J. Mater. Process. Technol., 2005, vols. 162-163, pp. 422-28. 